\title{
A Novel Small Molecule Inhibits Tumor Growth and Synergizes Effects of Enzalutamide on Prostate Cancer ${ }^{\mathrm{S}}$
}

\author{
(Diongjia Cheng, Stephanie Moore, Jorge Gomez-Galeno, Dong-Hoon Lee, \\ Karl J. Okolotowicz, and (1)John R. Cashman
}

Human BioMolecular Research Institute and ChemRegen Inc., San Diego, California

Received July 2, 2019; accepted September 27, 2019

\begin{abstract}
Prostate cancer $(\mathrm{PCa})$ is the second leading cause of cancerrelated death for men in the United States. Approximately $35 \%$ of $\mathrm{PCa}$ recurs and is often transformed to castration-resistant prostate cancer (CRPCa), the most deadly and aggressive form of PCa. However, the CRPCa standard-of-care treatment (enzalutamide with abiraterone) usually has limited efficacy. Herein, we report a novel molecule (PAWI-2) that inhibits cellular proliferation of androgen-sensitive and androgen-insensitive cells (LNCaP and PC-3, respectively). In vivo studies in a PC-3 xenograft model showed that PAWI-2 $(20 \mathrm{mg} / \mathrm{kg}$ per day i.p., 21 days) inhibited tumor growth by $49 \%$ compared with vehicletreated mice. PAWI-2 synergized currently clinically used enzalutamide in in vitro inhibition of PCa cell viability and resensitized inhibition of in vivo PC-3 tumor growth. Compared with vehicletreated mice, PC-3 xenograft studies also showed that PAWI-2 (20 mg/kg per day i.p., 21 days) and enzalutamide $(5 \mathrm{mg} / \mathrm{kg}$ per day i.p., 21 days) inhibited tumor growth by $63 \%$. Synergism was mainly controlled by the imbalance of prosurvival factors
\end{abstract}

(e.g., Bcl-2, Bcl-xL, Mcl-1) and antisurvival factors (e.g., Bax, Bak) induced by affecting mitochondrial membrane potential/ mitochondria dynamics. Thus, PAWI-2 utilizes a distinct mechanism of action to inhibit PCa growth independently of androgen receptor signaling and overcomes enzalutamide-resistant CRPCa.

\section{SIGNIFICANCE STATEMENT}

Castration-resistant prostate cancer (CRPCa) is the most aggressive human prostate cancer ( $\mathrm{PCa}$ ) but standard chemotherapies for CRPCa are largely ineffective. PAWI-2 potently inhibits $\mathrm{PCa}$ proliferation in vitro and in vivo regardless of androgen receptor status and uses a distinct mechanism of action. PAWI-2 has greater utility in treating CRPCa than standard-of-care therapy. PAWI-2 possesses promising therapeutic potency in low-dose combination therapy with a clinically used drug (e.g., enzalutamide). This study describes a new approach to address the overarching challenge in clinical treatment of CRPCa.

\section{Introduction}

In the United States, prostate cancer ( $\mathrm{PCa}$ ) was the second leading cause of cancer-related fatalities for men and resulted in an estimated 29,430 deaths in 2018 (Siegel et al., 2018). PCa alone accounts for $19 \%$ of all cancer cases in men (Siegel et al., 2018). PCa is often initially responsive to antiandrogen hormone therapies and is thus characterized as castrationsensitive PCa (Siegel et al., 2018). However, in $35 \%$ of patients, $\mathrm{PCa}$ recurs and is often transformed to castration-resistant prostate cancer (CRPCa), thus rendering hormone therapies ineffective (Gandhi et al., 2018; https://seer.cancer.gov/ csr/1975_2016/). This is an important distinction because

This work was supported by the National Institutes of Health National Cancer Institute [Small Business Innovation Research Program Grant R43CA203566 (to K.J.O.)] and the California Institute for Regenerative Medicine [Inception Award DISC1-10583 (to J.R.C.)] and by funds from the Human BioMolecular Research Institute and ChemRegen Inc.

https://doi.org/10.1124/jpet.119.261040.

S This article has supplemental material available at jpet.aspetjournals.org. the majority of $\mathrm{PCa}$ is nonlethal. The deadliest and most aggressive form of $\mathrm{PCa}$ is $\mathrm{CRPCa}$, which has a 40-month median survival (Karantanos et al., 2013; Katzenwadel and Wolf, 2015). Eighty percent of patients with PCa develop bone metastasis and have a 25\% 5-year survival (Sturge et al., 2011). Today, most patients who die from PCa have CRPCa. However, effective drugs to treat CRPCa are lacking. Standard-of-care treatment options for CRPCa are limited to radiation or hormone therapy (e.g., enzalutamide) (Tran et al., 2009; Schalken and Fitzpatrick, 2016) or are administered in combination with chemotherapy (e.g., docetaxel) (Mukherji et al., 2014).

The androgen receptor (AR), a steroid hormone receptor normally activated by androgens, plays an essential role in PCa development and progression (Gandhi et al., 2018). AR signaling is a critical survival pathway for PCa cells. Blockade of AR was shown to be an effective PCa therapeutic strategy (Tran et al., 2009; Schalken and Fitzpatrick, 2016). As one of the most effective AR-directed therapies, enzalutamide suppresses androgen action in PCa cells by inhibiting nuclear

ABBREVIATIONS: AR, androgen receptor; AST, aspartate aminotransferase; ATCC, American Type Culture Collection; Bak, Bcl-2-antagonist/killer protein; Bax, Bcl-2-associated X protein; Bcl-2, B-cell lymphoma 2; Bcl-xL, B-cell lymphoma-extra large; Cl, combination index; CRPCa, castrationresistant prostate cancer; HSP60, Heat shock protein 60; Mcl-1, Myeloid cell leukemia 1; PARP, poly(ADP)-ribose polymerase; PCa, prostate cancer; PCSD1, Prostate Cancer San Diego 1; TMRE, tetramethylrhodamine ethyl ester; TOM20, Translocase of outer mitochondrial membrane 20 homolog; VDAC1, Voltage dependent anion channel 1; WT, wild type. 
translocation, chromatin binding, and coregulator binding of AR (Tran et al., 2009). This overcomes resistance to conventional antiandrogens (https://www.cancernetwork.com/ articles/fda-approves-enzalutamide-xtandi-late-stage-prostatecancer). Use of enzalutamide increases overall survival by 2.5-5 months (Scher et al., 2012; Dhingra et al., 2013). However, survival benefits of enzalutamide were achieved in only about $50 \%$ of treated patients with PCa (Scher et al., 2012; Dhingra et al., 2013). Patients who initially respond to enzalutamide eventually develop acquired enzalutamide resistance that results in a shorter survival interval (Katzenwadel and Wolf, 2015; Schalken and Fitzpatrick, 2016). Combination treatment with enzalutamide and abiraterone (a CYP17 enzyme inhibitor that blocks adrenal androgen biosynthesis; de Bono et al., 2011) provided some improvement in PCa response. Clinical studies showed that this multicomponent therapy extended overall survival 4 to 5 months, but many untoward gastric and hematologic side effects were observed (Gandhi et al., 2018).
Moreover, the disease relapsed within 1 to 2 years in most responding patients, with evidence of renewed AR activity (de Bono et al., 2011; Scher et al., 2012; Dhingra et al., 2013). Therefore, novel therapeutic approaches to overcome castration resistance are urgently needed in the treatment of CRPCa.

As previously reported, a first-in-class nontoxic anticancer compound (PAWI-2; Fig. 1A) was developed by targeting protein components of dysregulated signal transduction pathways in cancer (Cashman et al., 2013; Cheng et al., 2018, 2019; Okolotowicz et al., 2018). PAWI-2 decreased cellular proliferation and induced apoptosis in several cancer cells (e.g., colon, breast, and pancreatic cancer) (Cashman et al., 2013; Cheng et al., 2018, 2019; Okolotowicz et al., 2018). PAWI-2 is a nontoxic DNA damage pathway inhibitor and activates mitochondrial-controlled p53-dependent apoptotic signaling (Cheng et al., 2018, 2019). Herein, we report that anticancer PAWI-2 (Fig. 1A) is an anti-PCa compound that works against androgen-sensitive PCa and androgen-insensitive CRPCa and
A<smiles></smiles>

PAWI-2

C

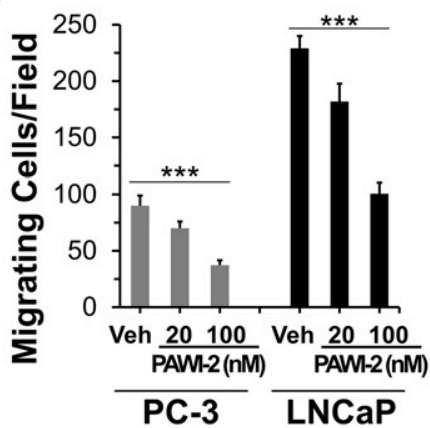

B

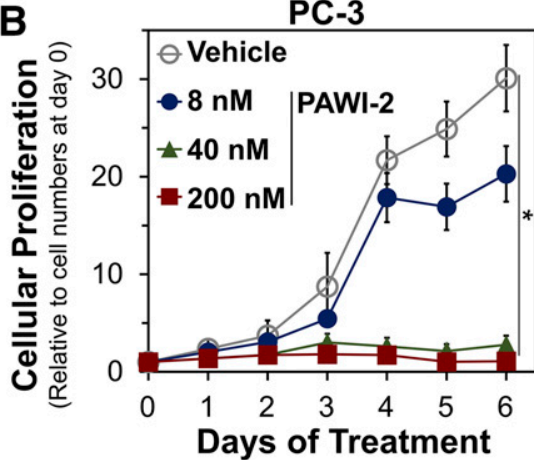

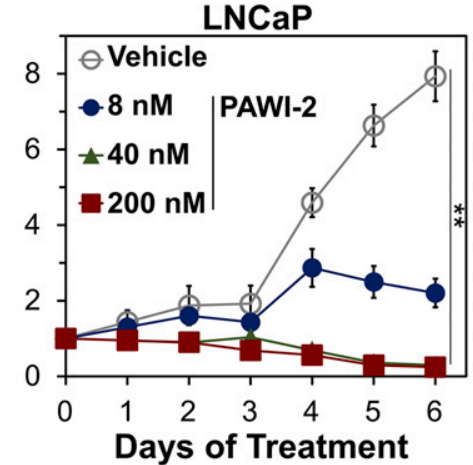

E

D

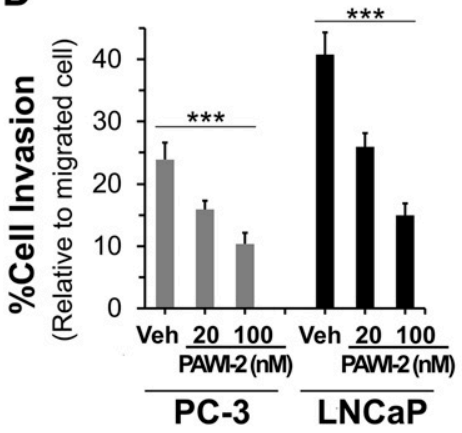

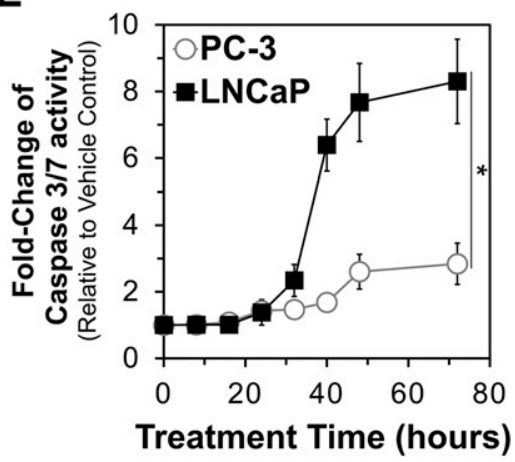

$\mathbf{F}$

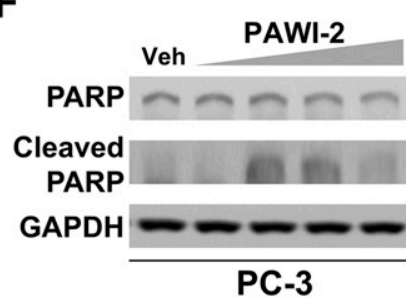

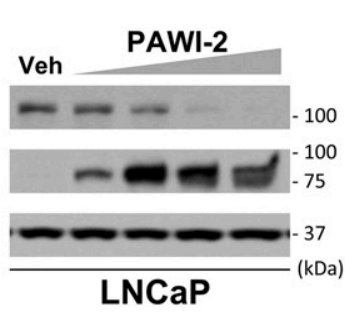

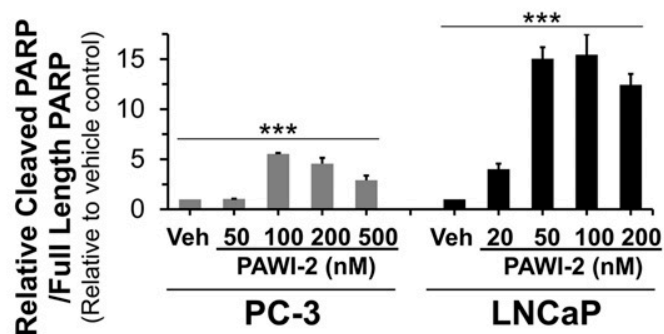

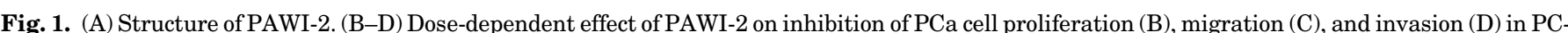

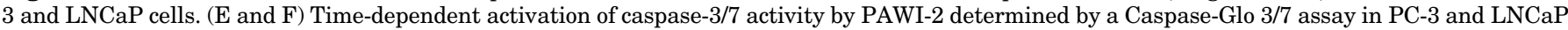

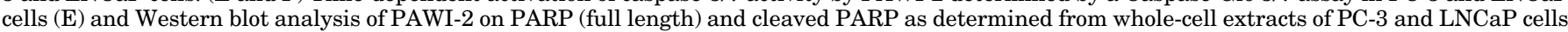

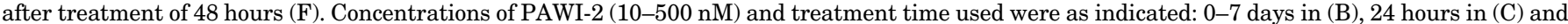

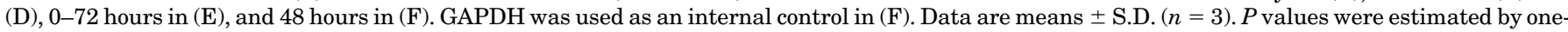

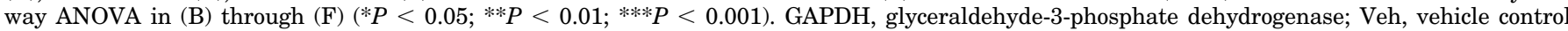
(0.5\% DMSO). 
also patient-derived bone niche PCa. PAWI-2 synergized currently clinically used enzalutamide in in vitro inhibition of PCa cell growth and also enhanced inhibition of tumor growth in a PC-3 xenograft model. PAWI-2 may afford more efficacious treatment with decreased side effects and also afford a molecule for both androgen-dependent and androgen-resistant PCa treatment.

\section{Materials and Methods}

Cell Lines. PC-3 (CRL-1435) and LNCaP (CRL-1740) PCa cells were purchased from American Type Culture Collection (ATCC). Prostate Cancer San Diego 1 (PCSD1) cells are a human prostate primary cancer cell freshly isolated from intrafemoral xenografts (generously provided by Dr. Christina Jamieson at Moores Cancer Center, University of California, San Diego) (Raheem et al., 2011; Godebu et al., 2014). Normal prostate epithelial cells (11220-hTERT) were kindly provided by Dr. John T. Isaacs (Graham et al., 2017) and grown in DermaLife keratinocyte serum-free medium (Lifeline Cell Technology). Commercial cell lines were grown according to ATCC recommendations and authenticated by short tandem repeat DNA profiling at ATCC. After thawing, cell lines were cultured at $37^{\circ} \mathrm{C}$ in a humidified $5 \% \mathrm{CO}_{2}$ atmosphere and routinely screened for mycoplasma contamination.

Compound Synthesis. The synthesis and pharmaceutical properties of PAWI-2 (Fig. 1A) were reported previously (Cashman et al., 2013; Okolotowicz et al., 2018).

Cell Viability and Apoptosis. PCa cells were seeded and treated with vehicle (0.5\% DMSO) or PAWI-2 (0.32-5000 nM). The effect of PAWI-2 on PCa (or 11220-hTERT) cell viability (72 hours) was determined by SYBR Green (cellular DNA detection) fluorescence intensity (with excitation/emission at 495/535 nm) (Cheng et al., 2018, 2019). Cellular proliferation was evaluated by determining the effect on cell viability at each day upon continuous 7-day treatment with PAWI-2. A similar protocol was used to test the synergy of PAWI-2 in the presence of enzalutamide and/or abiraterone. Chou-Talalay analysis was conducted with commercial software (ComboSyn) (Chou, 2010). Cell apoptosis was determined by a caspase-3/7 activity assay with the Caspase-Glo 3/7 assay kit (Promega) (Cheng et al., 2018, 2019).

Cell Migration and Invasion. PCa cells were pretreated with vehicle, PAWI-2 (20-100 nM), enzalutamide (500 nM), or in combination and were seeded in serum-free media on the upper side of a transwell chamber, either uncoated for a migration assay or coated with Matrigel (Corning) for invasion. Cells were allowed to migrate toward media containing 10\% FBS for 24 hours. After the incubation period, cells on the lower side of the membrane were fixed, stained ( $0.5 \%$ crystal violet), and counted under a microscope (five random fields at $40 \times$ magnification).

Tetramethyl Rhodamine Ethyl Ester Mitochondrial Membrane Potential. PCa cells were seeded and treated with vehicle, PAWI-2 (10-200 nM), enzalutamide (500 nM), and/or abiraterone (3 $\mu \mathrm{M}$ ) for 2-48 hours. Tetramethyl rhodamine ethyl ester (TMRE; 250 $\mathrm{nM}$ ) was added to cells in media and incubated for 30 minutes. The plate was depleted, washed, and equilibrated in PBS/0.2\% BSA (room temperature for 30 minutes) and fluorescence was read at excitation/ emission of 549/575 $\mathrm{nm}$ for calculation of the percentage of TMRE uptake compared with vehicle control.

Subcellular Fractionation and Immunoblotting. Subcellular fractionation and immunoblotting experiments were carried out as previously described (Cheng et al., 2019). Briefly, PCa cells were seeded and treated with vehicle or PAWI-2 (10-500 nM, 8-48 hours). Whole-cell extracts were obtained by lysis with radioimmunoprecipitation assay buffer (Supplemental Materials and Methods) and subcellular fractionations were obtained and homogenized. Protein extracts were resolved by SDS-PAGE followed by Western blotting using antibodies specific for proteins of interest (Supplemental
Materials and Methods). Densities of Western blot bands were quantified using NIH ImageJ software.

PC-3 Xenograft. Animal work was conducted in accordance with the Guide for the Care and Use of Laboratory Animals as adopted by the National Institutes of Health. Formal approval was obtained from the Human BioMolecular Research Institute Institutional Animal Care and Use Committee. Athymic nude mice (6-week-old males; Envigo) were anesthetized (xylazine/ketaved) and injected subcutaneously in the lower left flank with PC-3 cells (1 million log-phase cells in Matrigel matrix). Six days after cell implantation, animals with tumors were randomly assigned to four groups and injected intraperitoneally in the right lower abdomen area with aqueous polyethylene glycol $(0.1 \mathrm{ml}$; vehicle control), enzalutamide (5 mg/kg), PAWI-2 (20 mg/kg), or both PAWI-2 $(20 \mathrm{mg} / \mathrm{kg})$ and enzalutamide $(5 \mathrm{mg} / \mathrm{kg})$ formulated in aqueous polyethylene glycol (final concentration, $20 \% \mathrm{w} / \mathrm{v}$ ), respectively. Mice were monitored and dosed daily for 21 days and weighed once a week. Tumors were measured every 3 to 4 days by direct caliper measurements. At the end of the 26-day study, mice were killed and tumors were excised, weighed, and immunoblotted for analysis of select protein markers. Serum was obtained from blood samples for further analysis (IDEXX Laboratories).

Statistical Analysis. $\mathrm{IC}_{50}$ and $\mathrm{EC}_{50}$ values were calculated using a nonlinear regression analysis (GraphPad Prism) of the mean \pm S.D. or S.E.M. of at least triplicate samples for each biologic assay. Oneway ANOVA tests (post hoc Tukey test) or $t$ tests were used to calculate statistical significance (GraphPad Prism) and a $P$ value $<$ 0.05 was considered statistically significant.

\section{Results}

Effect of PAWI-2 on PCa Cell Viability, Proliferation, Migration, Invasion, and Apoptosis. PAWI-2 potently inhibited cell viability of the PCa cells examined $\left(\mathrm{IC}_{50}\right.$ values of 18 and $14 \mathrm{nM}$ for PC-3 and LNCaP, respectively, at 72 hours) (Table 1; Supplemental Fig. 1A). PAWI-2 also showed dosedependent inhibition of cellular proliferation in PCa cells upon continuous 7-day treatment (Fig. 1B). In an NCI-60 DTP human tumor cell line screen (Shoemaker, 2006), PAWI-2 potently inhibited cell proliferation against two CRPCa cell lines ( $\mathrm{IC}_{50}$ values of 34 and $46 \mathrm{nM}$ for PC-3 and DU-145, respectively). Inhibition by PAWI-2 was independent of AR response. Moreover, in human prostate primary cancer cells freshly isolated from intrafemoral xenografts (PCSD1) (Raheem et al., 2011; Godebu et al., 2014), PAWI-2 also potently inhibited cell viability $\left(\mathrm{IC}_{50}\right.$ of $60 \mathrm{nM}$; Table 1$)$. For comparison, PAWI-2 showed $<20 \%$ inhibition (at $5 \mu \mathrm{M}$, 72 hours) on normal prostate epithelia cell (11220-hTERT) viability (Supplemental Fig. 1A). PAWI-2 was also not acutely cytotoxic or genotoxic as reported previously (Cheng et al., 2018).

PAWI-2 inhibited PCa cell migration and invasion in a dosedependent manner (20-100 nM; Fig. 1, C and D). Compared with vehicle-treated PC-3 and LNCaP cells, PAWI-2 (100 nM, 24 hours) inhibited cell migration and invasion $>2$-fold. There was no significant inhibition on cell viability by PAWI-2 observed at this time point (24 hours; Supplemental Fig. 2).

PAWI-2 potently activated apoptosis (i.e., activation of caspase-3/7 activity; Fig. 1E; Supplemental Fig. 1B) in LNCaP cells (PAWI-2, $35 \mathrm{nM}$; 8-fold to vehicle control at 48 hours). However, the effect was less apparent in PC-3 cells (PAWI-2, $100 \mathrm{nM} ; 2.5$-fold at 48 hours). Apoptosis was not observed in normal prostate epithelia cells (11220-hTERT; Supplemental Fig. 1B) treated with PAWI-2 (0.32 nM to $5 \mu \mathrm{M}$; 24 hours). $\mathrm{EC}_{50}$ values for induction of apoptosis by PAWI-2 were 
TABLE 1

Effect of PAWI-2 on PCa cell viability and apoptosis and genomic and expression phenotypes of PCa cell lines used in this study

\begin{tabular}{|c|c|c|c|c|c|}
\hline Cell Line & Viability $\mathrm{IC}_{50}{ }^{a}$ & Apoptosis $\mathrm{EC}_{50}$ & TP53 Alleles & AR Expression & Androgen Response \\
\hline \multicolumn{6}{|c|}{$n M(n)$} \\
\hline PC-3 & $18 \pm 6(8)$ & $35 \pm 5(6)$ & fs-sc/del & - /low & AI \\
\hline $\mathrm{LNCaP}$ & $14 \pm 4(8)$ & $11 \pm 3(6)$ & WT/WT & + & $\mathrm{AD}$ \\
\hline PCSD $^{b}$ & $60 \pm 8(3)$ & & Unknown & Unknown & Unknown \\
\hline
\end{tabular}

$\mathrm{AD}$, androgen-dependent growth; AI, androgen-independent growth; del, allele deletion; fs-sc, frame shift producing a stop codon; TP53, human p53 gene.

${ }^{a} \mathrm{IC}_{50}$ or $\mathrm{EC}_{50}$ is the mean \pm the S.D. of three to eight independent determinations in the presence of PAWI- 2 . $n$ is the number of replicate experiments shown in parentheses.

${ }^{b}$ PCSD1 cells were human prostate primary cancer cells freshly isolated from intrafemoral xenografts (from Dr. Christina Jamieson, Moores Cancer Center, University of California, San Diego) (Raheem et al., 2011; Godebu et al., 2014).

consistent with $\mathrm{IC}_{50}$ values for inhibition of cell viability in LNCaP cells $\left(\mathrm{EC}_{50}\right.$ of $11 \mathrm{nM}$ vs. $\mathrm{IC}_{50}$ of $\left.14 \mathrm{nM}\right)$ but were 2 -fold greater in PC-3 cells $\left(\mathrm{EC}_{50}\right.$ of $35 \mathrm{nM}$ vs. $\mathrm{IC}_{50}$ of $\left.18 \mathrm{nM}\right)$ (Table 1). Stimulation of apoptosis by PAWI-2 was apparently dependent on the presence of full-length p53 protein because apoptosis was somewhat less apparent for PAWI-2 in PC-3 cells with a p53 frameshift/premature stop mutation (van Bokhoven et al., 2003). This result was consistent with previous reports of the effect of PAWI-2 in other cancer types (e.g., colon, breast, pancreatic cancer) (Cheng et al., 2018, 2019; Okolotowicz et al., 2018). P53-dependent apoptosis was observed by immunoblot results of poly(ADP)-ribose polymerase (PARP) cleavage. PAWI-2 (20-500 nM) potently induced cleavage of PARP ( 48 hours; Fig. 1F) in LNCaP cells but less potently in PC-3 cells. For example, $\mathrm{EC}_{50}$ values of PAWI2 for PARP cleavage (48 and $12 \mathrm{nM}$ in PC-3 and LNCaP, respectively) were similar to $\mathrm{EC}_{50}$ values observed for in vitro caspase activation (35 and $11 \mathrm{nM}$ for PC-3 and $\mathrm{LNCaP}$, respectively; Table 1 ).

Synergistic Effect of PAWI-2 with Enzalutamide in PCa Cells. Compared with PAWI-2, enzalutamide, abiraterone, or a combination was less efficient at inhibiting in vitro cell viability in $\mathrm{LNCaP}$ cells $\left(\mathrm{IC}_{50}>2 \mu \mathrm{M}\right)$ and was not potent in PC-3 cells (Table 2). However, in the presence of relatively low concentrations of PAWI-2 (2-8 nM), enzalutamide showed potent dose-response inhibition (Supplemental Fig. 3) on the cell viability of both PC-3 and LNCaP cells. Compared with enzalutamide treatment alone, combination treatment (enzalutamide with PAWI-2) potently inhibited cell viability approximately 16 -fold greater in $\mathrm{LNCaP}$ cells $\left(\mathrm{IC}_{50}\right.$ of $0.14 \mu \mathrm{M}$ vs. approximately $2.3 \mu \mathrm{M}$; Table 2 ). In the presence of PAWI-2, enzalutamide was observed to resensitize its inhibition on PC-3 cell viability $\left(\mathrm{IC}_{50}\right.$ of $1.4 \mu \mathrm{M}$; Table 2$)$. However, the combination of abiraterone with PAWI-2 was less effective

TABLE 2

Effect of PAWI-2 on PCa cell viability in combination with enzalutamide or abiraterone

Data are presented as the mean $\mathrm{IC}_{50} \pm$ S.D. unless indicated otherwise.

\begin{tabular}{lccccc}
\hline & \multicolumn{5}{c}{ Cell Viability, Drug/Combination ${ }^{a}$} \\
\cline { 2 - 6 } Cell Line & Enza & Abi & Enza + Abi & Enza + PAWI-2 & Abi + PAWI-2 \\
\hline & & \multicolumn{4}{c}{$\mu M$} \\
PC-3 & $>10^{b}$ & $>10^{b}$ & $>10^{b}$ & $1.4 \pm 0.6$ & $>10^{b}$ \\
LNCaP & 2.3 & 6.2 & 2.5 & $0.14 \pm 0.04$ & 2.7 \\
\hline
\end{tabular}

Abi, abiraterone; Enza, enzalutamide.

${ }^{a}$ The concentration of PAWI- 2 was $8 \mathrm{nM}$ in PC-3 cells and $2 \mathrm{nM}$ in LNCaP cells, respectively.

${ }^{b}$ Compounds were not potent up to the $10 \mu \mathrm{M}$ treated concentration. because decreased $\mathrm{IC}_{50}$ values were not observed. Compared with enzalutamide alone (500 $\mathrm{nM}$ ) or enzalutamide and abiraterone (3 $\mu \mathrm{M})$, a combination of enzalutamide with PAWI-2 (10 nM) potently inhibited cell viability $(P<0.05$; Fig. $2 \mathrm{~A})$.

Based on Chou-Talalay synergism analysis (Table 3) (Chou, 2010), PAWI-2 synergized the inhibition of cell viability by enzalutamide against PC-3 and LNCaP cells and showed a low combination index (CI) value (0.48-0.76 in PC-3 and 0.13-0.37 in LNCaP; Table 3). Synergism between abiraterone and PAWI-2 was only observed in LNCaP cells (CI, 0.7-0.74; Table 3). Antagonism (CI > 1; Table 3) was observed between enzalutamide and abiraterone in either PC-3 or LNCaP cells. Combination treatment (enzalutamide + abiraterone + PAWI-2) showed less potent synergism compared with enzalutamide + PAWI-2.

Enhancement of inhibition of $\mathrm{PCa}$ cell migration and invasion was also observed in both PC-3 and LNCaP cells in the presence of enzalutamide with PAWI-2. Compared with enzalutamide alone in PC-3 and LNCaP cells, combination treatment (enzalutamide + PAWI-2) inhibited cell migration and invasion $>3$-fold greater (Fig. 2, B and C). However, there was also no significant inhibition of cell viability observed in this condition (Supplemental Fig. 2).

Mechanism Studies: Synergy of the Inhibitory Effect of PAWI-2 on Enzalutamide. Based on the effect of PAWI-2 on caspase-3/7 activity (35-100 nM PAWI-2 potently induced apoptosis), PAWI-2 in combination with enzalutamide was examined and compared with a combination of enzalutamide and abiraterone (Fig. 2D; Supplemental Fig. 4). In LNCaP cells, PARP cleavage, a direct apoptotic marker, was enhanced 1.6-fold by PAWI-2 in combination with enzalutamide (Supplemental Fig. 5). However, this effect was not observed in PC-3 cells. Synergistic inhibition against cell viability, cell migration, and invasion (CI values $<1$; Fig. 2 , A-C; Table 3) of enzalutamide with PAWI-2 was in part related to enhanced apoptosis. In PC-3 cells, apoptosis was induced by PAWI-2 alone (less potent than that in LNCaP cells) but combination treatment did not enhance apoptosis (Fig. 2D; Supplemental Fig. 4). Thus, induction of apoptosis may not be the sole mechanism of PAWI-2 to synergize the inhibitory effect of enzalutamide.

Enhancement of cell inhibition was p53 independent because synergism was observed in both PC-3 cells (TP53 alleles: fs-sc/del; Table 1) and LNCaP cells (TP53 alleles: wild type WT/WT; Table 1). Compared with PAWI-2 alone, neither total p53 (approximately 3-fold) nor phospho(Ser15)-p53 activation (approximately 20-fold) was enhanced by combination treatment in LNCaP cells (Supplemental Fig. 5). Ataxia telangiectasia and Rad3-related protein kinase (ATR) 

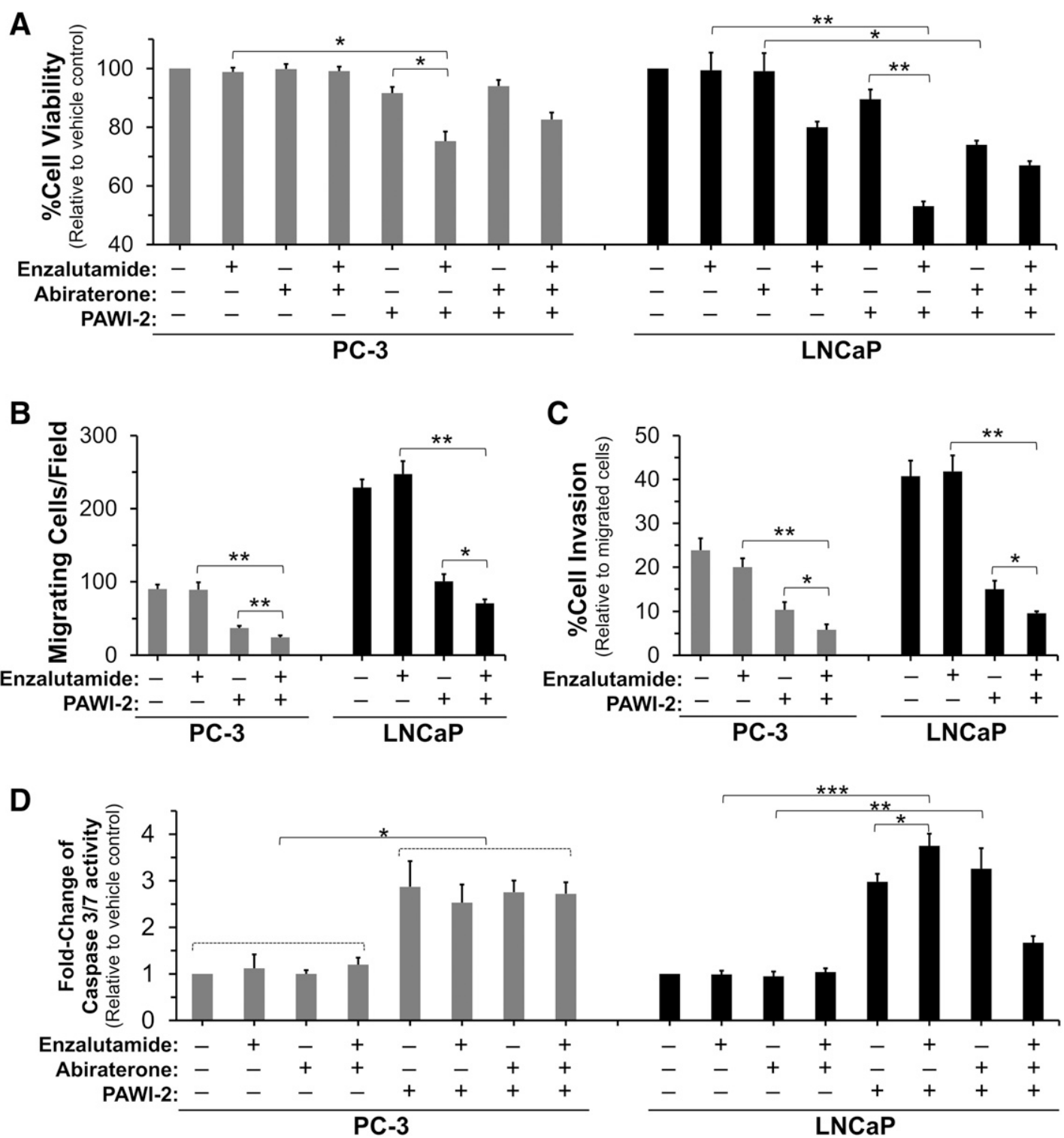

Fig. 2. (A-D) Effect of PAWI-2 on inhibition of PCa cell viability (A), migration (B), invasion (C), and activation of caspase-3/7 activity (D) in the presence of enzalutamide and/or abiraterone in PC-3 or LNCaP cells. Concentrations of enzalutamide and abiraterone treatment were $500 \mathrm{nM}$ and $3 \mu \mathrm{M}$, respectively. The concentrations of PAWI-2 used were as follows: $10 \mathrm{nM}(\mathrm{A}), 100 \mathrm{nM}$ (B, C, and PC-3 in D), and $20 \mathrm{nM}$ (LNCaP in D). Treatment time was 72 hours (A), 24 hours (B and C), and 48 hours (D). Data are means \pm S.D. $(n=3)$. $P$ values were estimated by the $t$ test $(* P<0.05 ; * * P<0.01 ; * * * P<$ 0.001). Veh, vehicle control (0.5\% DMSO).

autophosphorylation in PC-3 or LNCaP cells was also observed in PAWI-2-treated cells but was not enhanced in combination treatment (Supplemental Fig. 5).

Synergism between enzalutamide and PAWI-2 was associated with mitochondrial dysfunction observed by TMRE mitochondrial membrane potential $\left(\Delta \Psi_{m}\right)$ assessment (Fig. 3, A and B; Supplemental Fig. 6). Changes in mitochondrial membrane potential in $\mathrm{PCa}$ cells treated with PAWI-2, enzalutamide, or a combination were quantified by the percentage of TMRE uptake. TMRE accumulates in active mitochondria (Ehrenberg et al., 1988). $\mathrm{IC}_{50}$ values of PAWI-2 to inactivate mitochondria or cause mitochondrial membrane potential loss $\left(\mathrm{IC}_{50}\right.$ values of 46 and 23 $\mathrm{nM}$ in PC-3 and LNCaP cells, respectively; Fig. 3A) were similar to those values observed in other in vitro assays (Table 1). Compared with single or other compound combinations of enzalutamide and abiraterone, the combination of $500 \mathrm{nM}$ enzalutamide and 50-100 nM PAWI-2 (8 hours of treatment) showed the greatest inhibition of the percentage of TMRE uptake (20\%-25\% greater; Fig. 3B). Enhancement of the inhibition of TMRE uptake was associated with synergistic inhibition in enzalutamide + PAWI-2 combination treatment against cell viability, cell migration, and invasion (CI values $<1$; Fig. 2, A-C; Table 3).

We characterized the effect of enzalutamide, PAWI-2, or a combination of enzalutamide and PAWI-2 on mitochondrialassociated B-cell lymphoma 2 (Bcl-2) family proteins (Fig. 3C) compared with other mitochondrial protein (e.g., matrix protein: Heat shock protein 60 (HSP60); membrane proteins: Translocase of outer mitochondrial membrane 20 homolog (TOM20) and Voltage dependent anion channel 1 (VDAC1) ). Prosurvival factors (e.g., Bcl-2, B-cell lymphoma-extra large 
TABLE 3

Summary of CI values to quantify synergism

Data are the results of Chou-Talalay analysis of treatment of PAWI-2 with enzalutamide and/or abiraterone in PC-3 and LNCaP PCa cells.

\begin{tabular}{llcccc}
\hline \multirow{3}{*}{ Cell Line } & \multicolumn{1}{c}{ Drug/Combination ${ }^{a}$} & \multicolumn{3}{c}{ CI Values at Different EDs $^{b}$} \\
\cline { 3 - 6 } & & $\mathrm{ED}_{50}$ & $\mathrm{ED}_{75}$ & $\mathrm{ED}_{90}$ & $\mathrm{ED}_{95}$ \\
\hline \multirow{2}{*}{ PC-3 } & Enza + Abi & $>50$ & $>50$ & $>50$ & $>50$ \\
& Enza + PAWI-2 & 0.97 & $0.76^{c}$ & $0.54^{c}$ & $0.48^{c}$ \\
& Abi + PAWI-2 & 0.97 & 0.92 & 0.92 & 1.10 \\
LNCaP & Enza + Abi + PAWI-2 & 1.30 & 0.97 & $0.72^{c}$ & $0.58^{c}$ \\
& Enza + Abi & 1.39 & 1.79 & 1.97 & 2.03 \\
& Enza + PAWI-2 & $0.76^{c}$ & $0.37^{c}$ & $0.19^{c}$ & $0.13^{c}$ \\
& Abi + PAWI-2 & $0.78^{c}$ & $0.74^{c}$ & $0.72^{c}$ & $0.70^{c}$ \\
& Enza + Abi + PAWI-2 & 0.92 & 0.97 & 1.03 & 1.08 \\
\hline
\end{tabular}

\footnotetext{
Abi, abiraterone; Enza, enzalutamide.

${ }^{a}$ The ratios of Enza/PAWI-2 and Abi/PAWI-2 were 5:1 and 30:1 in PC-3 cells and 25:1 and 150:1 in LNCaP cells, respectively.

${ }^{b} \mathrm{CI}$ values were calculated based on the Chou-Talalay method (Chou, 2010). CI values $<1,1$, and $>1$ indicate synergism, additive, and antagonism, respectively. $\mathrm{ED}_{50}, \mathrm{ED}_{75}, \mathrm{ED}_{90}$, and $\mathrm{ED}_{95}$ represent concentrations that cause $50 \%, 75 \%, 90 \%$, and $95 \%$ of proliferation inhibition, respectively.

${ }^{c}$ These values show synergy.
}

(Bcl-xL), Myeloid cell leukemia 1 (Mcl-1) ) were upregulated by enzalutamide treatment in PCa cells. These proteins are either partially localized or exclusively integrated to the outer mitochondrial membrane to exert their functions (Wiedemann and Pfanner, 2017). PAWI-2 treatment alone caused mild degradation of outer mitochondrial membrane proteins. In the presence of enzalutamide, PAWI-2 attenuated Bcl-2, Bcl-xL, and Mcl-1 protein levels back to normal. In contrast, antisurvival factors (e.g., Bcl-2-associated X protein (Bax), Bcl-2antagonist/killer protein (Bak)) were activated due to feedback control, the levels of which were unaffected or upregulated by PAWI-2 or enzalutamide + PAWI-2 treatment. This facilitated incipient cytochrome $c$ release followed by cell growth inhibition. For comparison, the levels of other mitochondrial localized proteins (e.g., HSP60, TOM20, VDAC1) were not affected by PAWI-2 (Fig. 3C).

Effect of PAWI-2 on Tumor Growth in a PC-3 Xenograft Model. Previous pharmacokinetics, pharmacodynamic, and absorption, distribution, metabolism, and excretion studies showed that PAWI-2 possessed sufficient chemical and metabolic stability, bioavailability, and druglike properties to examine its efficacy in vivo (Cheng et al., 2018, 2019; Okolotowicz et al., 2018). Efficacy of PAWI-2 was examined either as a single agent or in combination with enzalutamide in a PC-3 xenograft animal model. Throughout the 26-day study, there was no statistically significant difference in animal body weight (Fig. 4A). None of the mice died prior to day 26 and all appeared normal and vigorous. Animals with tumors established (on day 6; average size, $63 \mathrm{~mm}^{3}$ ) were treated with vehicle, enzalutamide, PAWI-2, or enzalutamide + PAWI-2. Compared with vehicle-treated animals, PAWI-2 (20 mg/kg per day i.p., 21 consecutive days) or enzalutamide ( $5 \mathrm{mg} / \mathrm{kg}$ per day i.p., 21 consecutive days) with PAWI-2 (20 mg/kg per day i.p., 21 consecutive days) decreased the $\mathrm{PC}-3$ tumor growth rate in mice (Fig. 4B). Vehicle-treated animals grew tumors to an average size of $332 \mathrm{~mm}^{3}$ (5.7-fold increase; Fig. 4B) at day 26. In comparison, treatment with enzalutamide alone, PAWI-2 alone, or enzalutamide + PAWI-2 decreased the tumor growth rate $15 \%, 49 \%$, and $63 \%$, respectively (relative to the vehicle-treated group).
At the end of the study, excised tumor volumes and weights of PAWI-2-treated mice ( $20 \mathrm{mg} / \mathrm{kg}$ per day) were significantly lower than those of vehicle-treated mice $(P<0.05 ; 50 \%$ and $49 \%$ relative to the vehicle group, respectively; Fig. 4, C and D). Excised tumor volumes and weights of enzalutamide + PAWI-2-treated mice were significantly lower than those of mice treated with enzalutamide alone $(P<0.05 ; 48 \%$ and $44 \%$ relative to enzalutamide-treated group, respectively; Fig. 4, C and D). For comparison, enzalutamide alone decreased tumor volume and tumor weight only $5 \%$ and $27 \%$, respectively, compared with the vehicle-treated group. PAWI-2 significantly decreased PC-3 tumor growth in vivo and also resensitized the effect of enzalutamide inhibition. Combination treatment (enzalutamide + PAWI-2) inhibited tumor weight (additional 18\% decrease) greater than PAWI-2 alone (Fig. 4D).

There was no significant difference in serum clinical parameters between the groups except the value of serum glutamic oxaloacetic transaminase [aspartate aminotransferase (AST)] in mice treated with enzalutamide alone (Supplemental Table 1). In mice with combination treatment (enzalutamide + PAWI-2), PAWI-2 decreased serum glutamic pyruvic transaminase (alanine aminotransferase), serum glutamic oxaloacetic transaminase (AST), and glucose levels induced by enzalutamide treatment. Serum clinical data suggested that treatment of animals with PAWI-2 (20 mg/kg per day i.p., 21 days) showed normal liver, kidney, or blood parameters. Moreover, PAWI-2 in combination with enzalutamide may decrease some side effects of enzalutamide treatment, like the most common hepatic effects with increased AST and alanine aminotransferase levels (Beer et al., 2018).

Immunoblot Analysis of PC-3 Tumors Excised from Xenografts. Tumors excised from animals upon termination of the xenograft study were analyzed for phosphorylatedAtaxia telangiectasia mutated kinase (ATM), Bcl-xL, Bak, cytochrome $c$, or PARP proteins by immunoblots (Fig. 5). DNA damage marker phosphorylated-Ataxia telangiectasia mutated kinase (ATM) was not measurably affected across the groups. Prosurvival factor Bcl-xL was modestly upregulated (1.4-fold) in the presence of enzalutamide but returned back to normal levels in enzalutamide + PAWI-2-treated tumors. Compared with vehicle-treated mice, animals treated with PAWI-2 alone or a combination of enzalutamide + PAWI-2 had on average 1.9- and 2.5-fold and 2.3- and 3.5-fold greater protein levels of Bak and cytochrome $c$, respectively (Fig. 5B). The effect of PAWI-2 or enzalutamide + PAWI-2 on protein markers in tumor tissue extract was consistent with in vitro PC-3 cell studies (Figs. 1F and 3C; Supplemental Fig. 5). A similar effect on Bcl-xL, Bak, and cytochrome $c$ was observed. The resensitizing effect of PAWI-2 on enzalutamide was mainly due to the imbalance of prosurvival factors (e.g., Bcl-xL) and antisurvival factors (e.g., Bak) induced by PAWI-2. In contrast, animals treated with enzalutamide alone did not show any apparent increased levels of PARP cleavage, Bak, or cytochrome $c$. Compared with vehicle-treated mice, animals treated with PAWI-2 alone or enzalutamide + PAWI-2 had a 4-fold increase in PARP cleavage (Fig. 5B), indicative of induced apoptosis in these excised tumors. However, PARP cleavage may not recapitulate the resensitized effect of enzalutamide because there was no enhancement of PARP cleavage upon comparison of enzalutamide + PAWI-2 to PAWI-2 alone. 
A

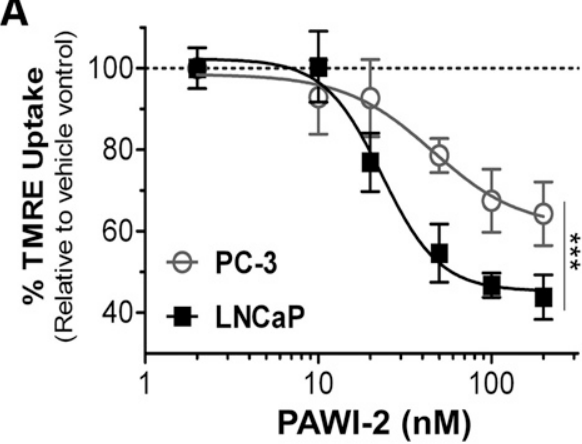

B

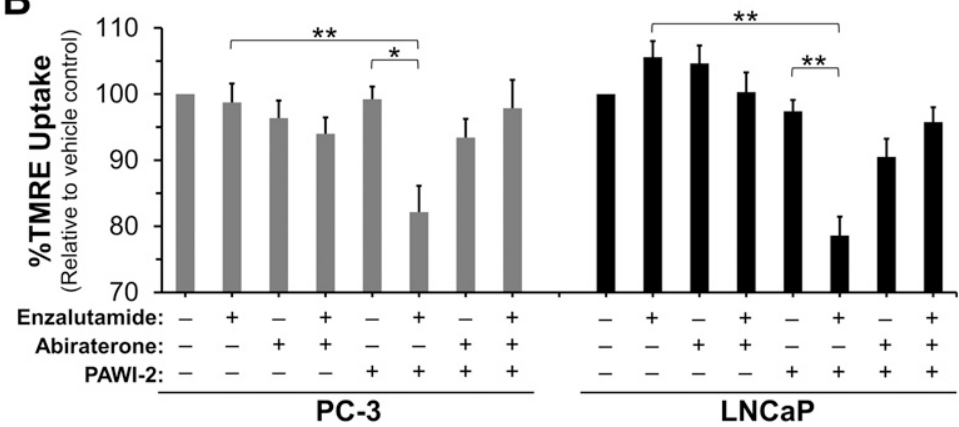

C
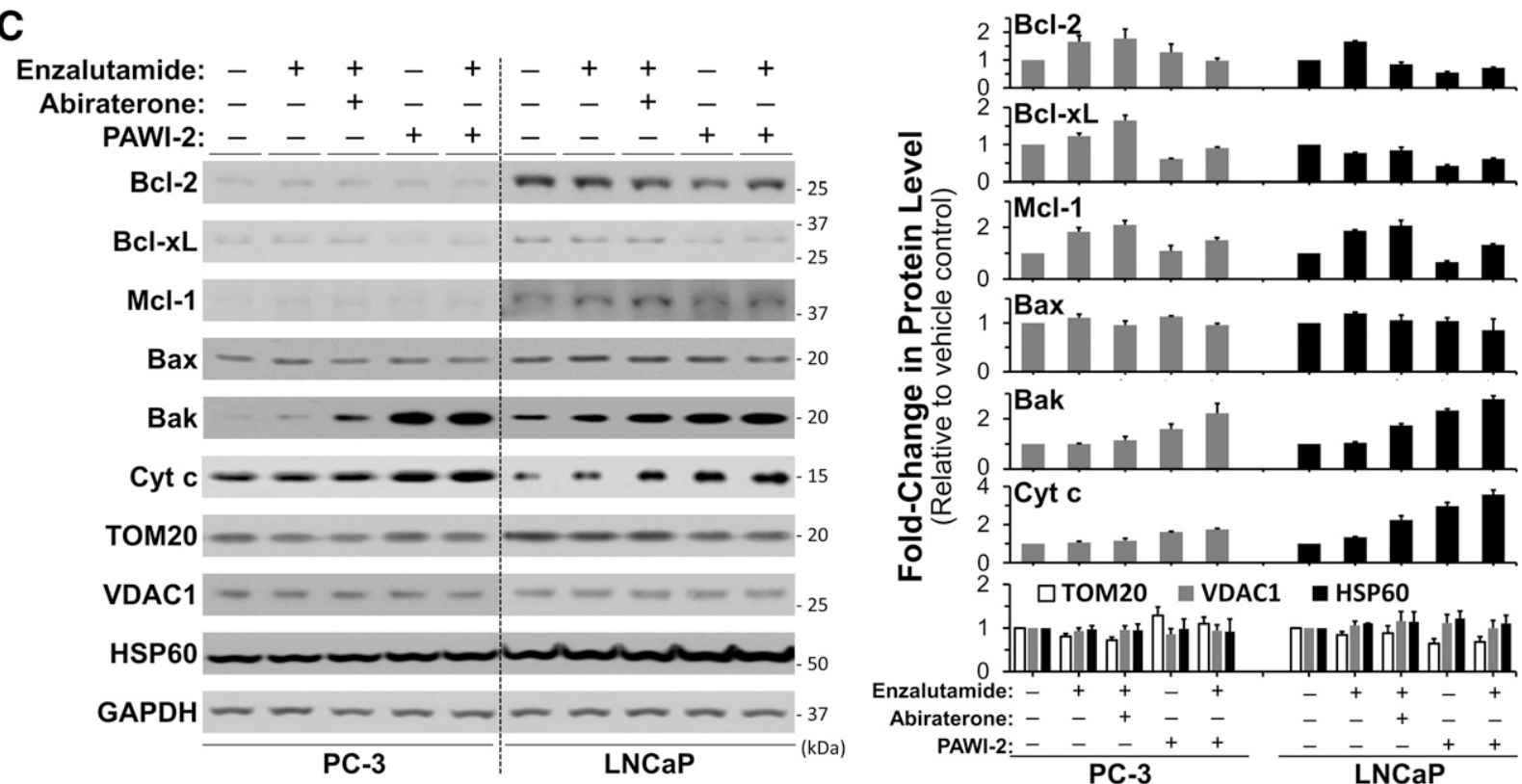

Fig. 3. (A-C) Effect of PAWI-2 on changes of mitochondrial membrane potential determined by TMRE assay (A and B) and Western blotting of mitochondrial proteins (C) in the presence of enzalutamide. Dose-dependent inhibition of the percentage of TMRE (\%TMRE) uptake by PAWI-2 (2-200 nM) (A), enhancement of enzalutamide on inhibition of \%TMRE uptake by PAWI-2 (B), and Western blot analysis of Bcl-2, Bcl-xL, Mcl-1, Bax, Bak, cytochrome $c$ (Cyt c), TOM20, VDAC1, and HSP60 by PAWI-2 as determined from mitochondrial extracts of PC-3 and LNCaP cells (C). Concentrations of enzalutamide and abiraterone treatment were $500 \mathrm{nM}$ and $3 \mu \mathrm{M}$, respectively. Concentrations of PAWI-2 were $100 \mathrm{nM}$ in PC-3 and $50 \mathrm{nM}$ in LNCaP. Treatment time was 24 hours (A and C) and 8 hours (B). GAPDH was used as an internal control in (C). Data are means \pm S.D. $(n=3)$. $P$ values were estimated by the one-way ANOVA test in (A) $(* * * P<0.001)$ and by the $t$ test in $(\mathrm{B})(* P<0.05 ; * * P<0.01)$. GAPDH, glyceraldehyde-3-phosphate dehydrogenase; Veh, vehicle control (0.5\% DMSO).

\section{Discussion}

As previously reported (Cheng et al., 2018), PAWI-2 binds tubulin to cause tubulin destabilization (acetylated tubulin inhibition, $\mathrm{IC}_{50}$ values of $150-400 \mathrm{nM}$; 10 - to 20 -fold greater $\mathrm{IC}_{50}$ values than that observed in other in vitro pathways, with $\mathrm{IC}_{50}$ values of $10-20 \mathrm{nM}$ ) (Cheng et al., 2018, 2019). Even though PAWI-2 was found to destabilize microtubules in PCa cells in a similar manner to that observed in other cancer types (approximately 2 -fold inhibition of acetylated tubulin levels at $200 \mathrm{nM}$; Supplemental Fig. 7A), we favor a model that PAWI-2 causes partial inhibition of tubulin acetylation to "sense" and activate the DNA damage checkpoint and apoptosis in mitochondrial p53-dependent pathways in cancer (Cheng et al., 2018, 2019). In addition, synergism of enzalutamide + PAWI-2 was also not due to tubulin destabilization because inhibition of acetylated tubulin levels was not observed (Supplemental Fig. 7B) at the dose of PAWI-2 examined (50-100 nM). Accordingly, we surmised that tubulin binding by PAWI-2 was not fully responsible for the pharmacological effects observed. The lack of stimulation of cell apoptosis by PAWI-2 in p53-deficient cells (Cheng et al., 2018, 2019) showed that p53 played a significant role in the mechanism of action of PAWI-2 to induce cell apoptosis. P53 dependence of PAWI-2 was also observed in PCa cells (Fig. 1, E and F) because apoptosis induced by PAWI-2 was significantly greater in LNCaP (WT p53) than that in PC-3 (similar to null p53 status). However, there was no apparent relationship observed between p53 mutation status and potency of PAWI-2 in inhibiting PCa cell viability (Table 1). There was also no apparent relationship between p53 status and synergism of PAWI-2 + enzalutamide in PCa cells (Fig. 2, A-C; Table 3). P53 activation may not be completely responsible for the potency of PAWI-2 in the presence of enzalutamide. Synergistic inhibition of PCa cell growth of PAWI-2 + enzalutamide may be affected by more complex factors.

Expression of AR in $\mathrm{PCa}$ is heterogeneous. $\mathrm{PCa}$ cells are often classified as $\mathrm{AR}$-expressing (i.e., $\mathrm{AR}^{+}, \mathrm{LNCaP}$ ) and $\mathrm{AR}$ low- or nonexpressing (i.e., $\mathrm{AR}^{-1 \mathrm{o}}, \mathrm{PC}-3$ ) cells (van Bokhoven 
A

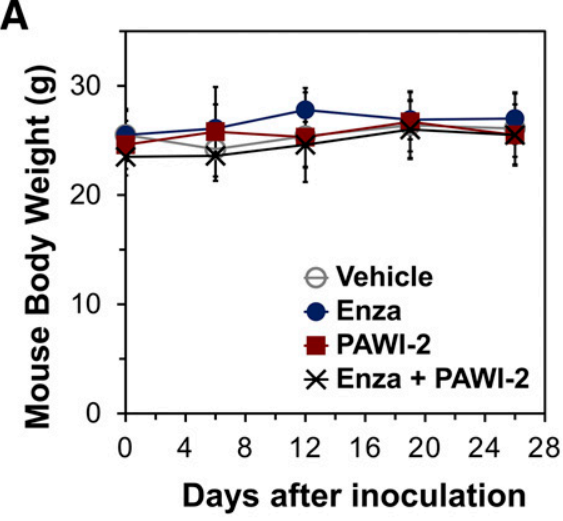

C

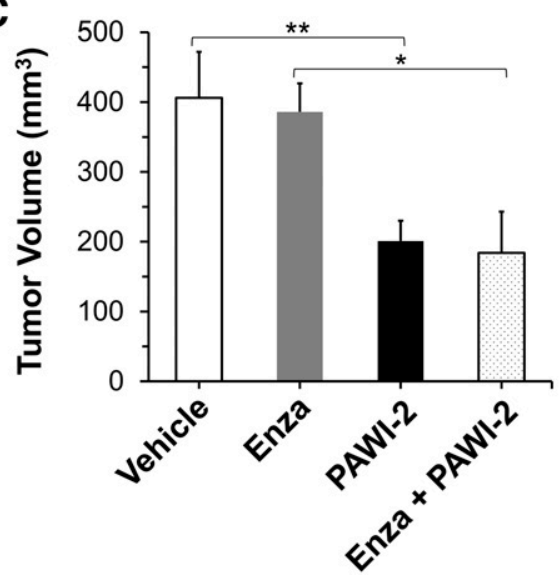

B
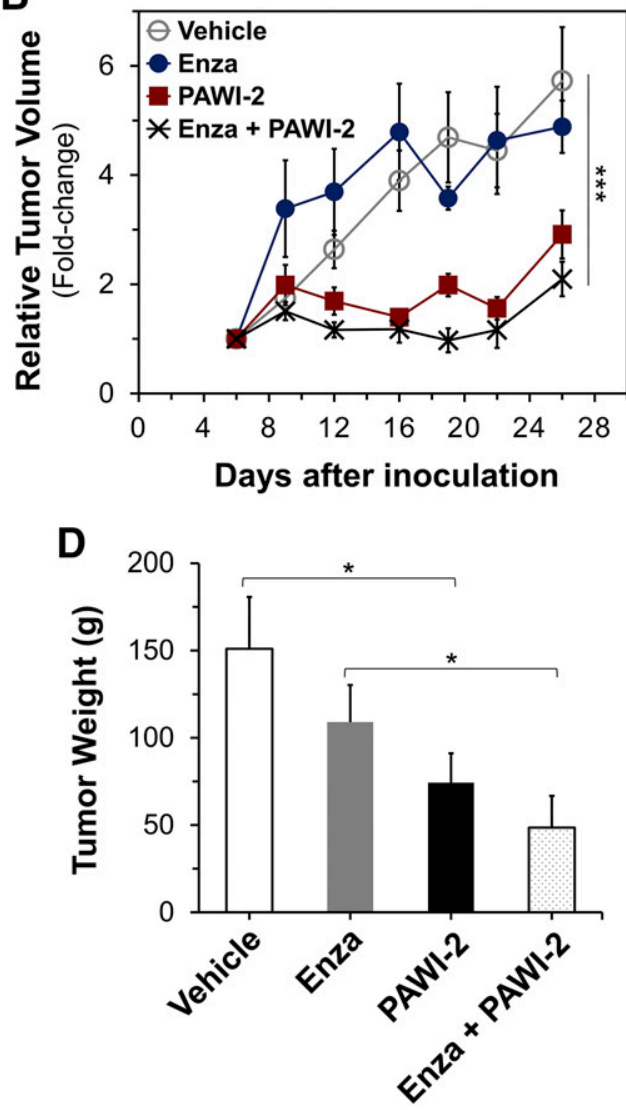

Fig. 4. Effect of PAWI-2 on PC-3 tumor growth in a subcutaneous xenograft model in nu/nu mice. (A-D) Average xenograft mice body weight (in grams) (A), average tumor growth (B), tumor volume (in cubic millimeters) (C), and weight (in grams) (D) for excised tumors of animals treated with vehicle, enzalutamide, PAWI-2, or enzalutamide + PAWI-2 (Enza + PAWI-2). Treatment was administered every day for 21 days starting on day 6 after PC-3 cell inoculation by intraperitoneal injection. Body weights were monitored once a week after inoculation. Tumors implanted in nu/nu mice were assessed by caliper measurements every 3 to 4 days after inoculation. Dose treatment was as follows: vehicle control (aqueous polyethylene glycol), $n=$ 9; enzalutamide ( $5 \mathrm{mg} / \mathrm{kg}$ per day), $n=9$; PAWI-2 (20 mg/kg per day), $n=9$; or both enzalutamide $(5 \mathrm{mg} / \mathrm{kg}$ per day) and PAWI-2 $(20 \mathrm{mg} / \mathrm{kg}$ pe day), $n=6$. Data are means \pm S.E.M. $P$ values were estimated by one-way ANOVA in (B) $(* * * P<0.001)$ and by the $t$ test in $(\mathrm{C})$ and (D) $(* P<0.05$; ** $P<0.01)$. et al., 2003). $\mathrm{AR}^{-/ \mathrm{lo}} \mathrm{PCa}$ cells are resistant to inhibition of cell viability for most commonly used therapy for androgen ablation (Katzenwadel and Wolf, 2015). For example, enzalutamide is an AR antagonist approved by the U.S. Food and Drug Administration in 2012 (https://www.cancernetwork. com/articles/fda-approves-enzalutamide-xtandi-late-stageprostate-cancer) and has been reported to be effective in the treatment of $\mathrm{PCa}$. Most $\mathrm{AR}^{+} \mathrm{PCa}$ reportedly responds to androgen ablation therapies but often leads to androgendepletion independent status (Karantanos et al., 2013; Katzenwadel and Wolf, 2015). The currently incurable stage of PCa (CRPCa) remains a challenge to treat (Yang et al., 2009; Ni et al., 2013; Ritch and Cookson, 2016; Jernberg et al., 2017). The combination of enzalutamide with abiraterone is the most widespread first-line treatment of CRPCa (de Bono et al., 2011). In enzalutamide-sensitive LNCaP cells and enzalutamideresistant PC-3 cells, enzalutamide + PAWI-2 markedly increased the inhibition of $\mathrm{PCa}$ cell viability compared with enzalutamide alone or enzalutamide + abiraterone (Tables 2 and 3). Thus, PAWI-2 sensitized these cells to enzalutamide much more effectively than abiraterone. Greater than $90 \%$ of patients develop metastases from CRPCa that cause PCarelated deaths (Gandhi et al., 2018). Because cancer metastasis is a hallmark of malignancy in CRPCa, the finding that PAWI-2 inhibited PCa migration and invasion regardless of AR response status (Fig. 1, C and D) and also synergized/ resensitized the effect of enzalutamide (Fig. 2, B and C) is an important finding. Moreover, PAWI-2 also potently inhibited cell viability of bone metastatic CRPCa cells (PCSD1) (Raheem et al., 2011; Godebu et al., 2014). In summary, PAWI-2 is capable of interrupting highly invasive and metastatic properties of CRPCa.

Recent reports suggest that in addition to nuclear genomic signaling, AR may also participate in nongenomic signaling in $\mathrm{PCa}$ (i.e., control of mitochondrial function and retrograde signaling; Massie et al., 2011; Zarif and Miranti, 2016). The mechanism of action of PAWI-2 was previously reported to be closely allied to mitochondrial function (Cheng et al., 2019). Herein, we showed that PAWI-2 causes the loss of mitochondrial membrane potential and affects mitochondrial membrane dynamics and import/translocation of proteins (e.g., degradation of several mitochondrial localized Bcl-2-like proteins; Fig. 3C). This effect was independent of AR status and also highly associated with synergism for enzalutamide + PAWI-2. Other mitochondrial localized proteins (e.g., HSP60, TOM20, or VDAC1) control general mitochondrial import machinery and mitochondrial respiration, the levels of which were not affected by PAWI-2. PAWI-2 may selectively affect the Bcl-2 family of proteins but not disrupt entire mitochondria integrity. There are other $\mathrm{PCa}$ drugs that reportedly interfere with mitochondrial membrane potential (e.g., docetaxel) (Mediavilla-Varela et al., 2009).

There are currently only a few medications or treatments approved to treat CRPCa, including docetaxel, cabazitaxel, abiraterone, enzalutamide, and Radium-223 (Karantanos et al., 2013). Among these, enzalutamide is well tolerated and has a favorable toxicity profile (Tran et al., 2009). However, enzalutamide treatment outcomes remain modest. In a human CRPCa xenograft model (VCaP), enzalutamide $(10 \mathrm{mg} / \mathrm{kg}$ per day p.o., 26 days) inhibited tumor growth 10\% (Qiao et al., 2016). In another 


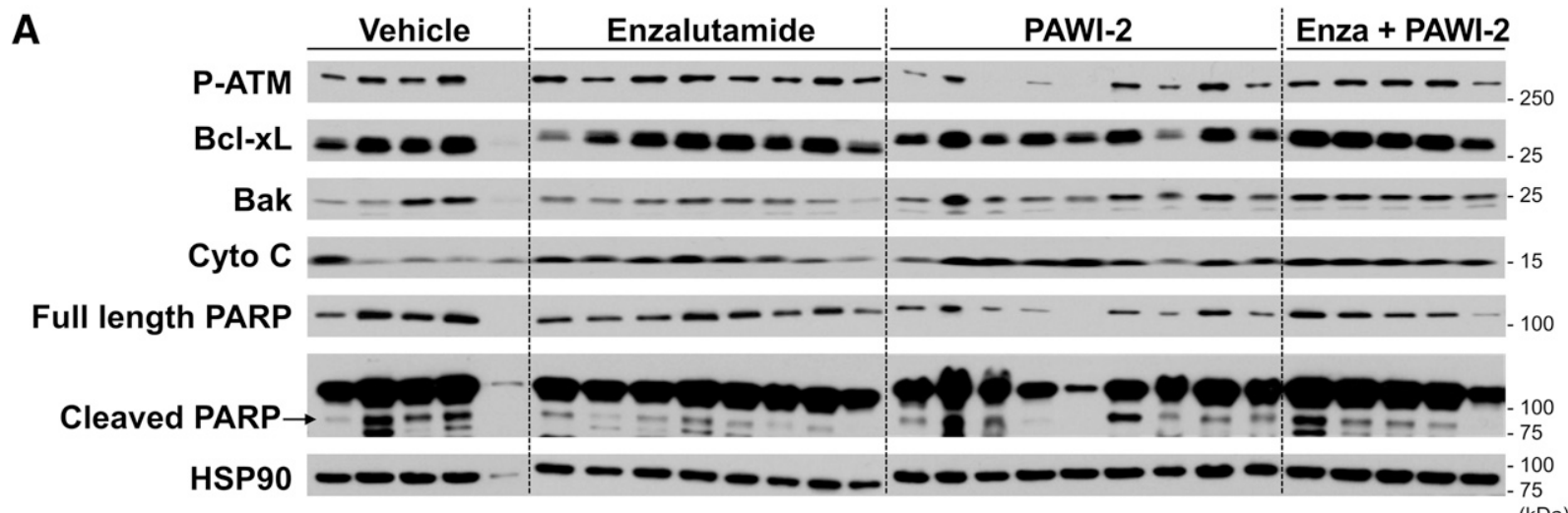

B
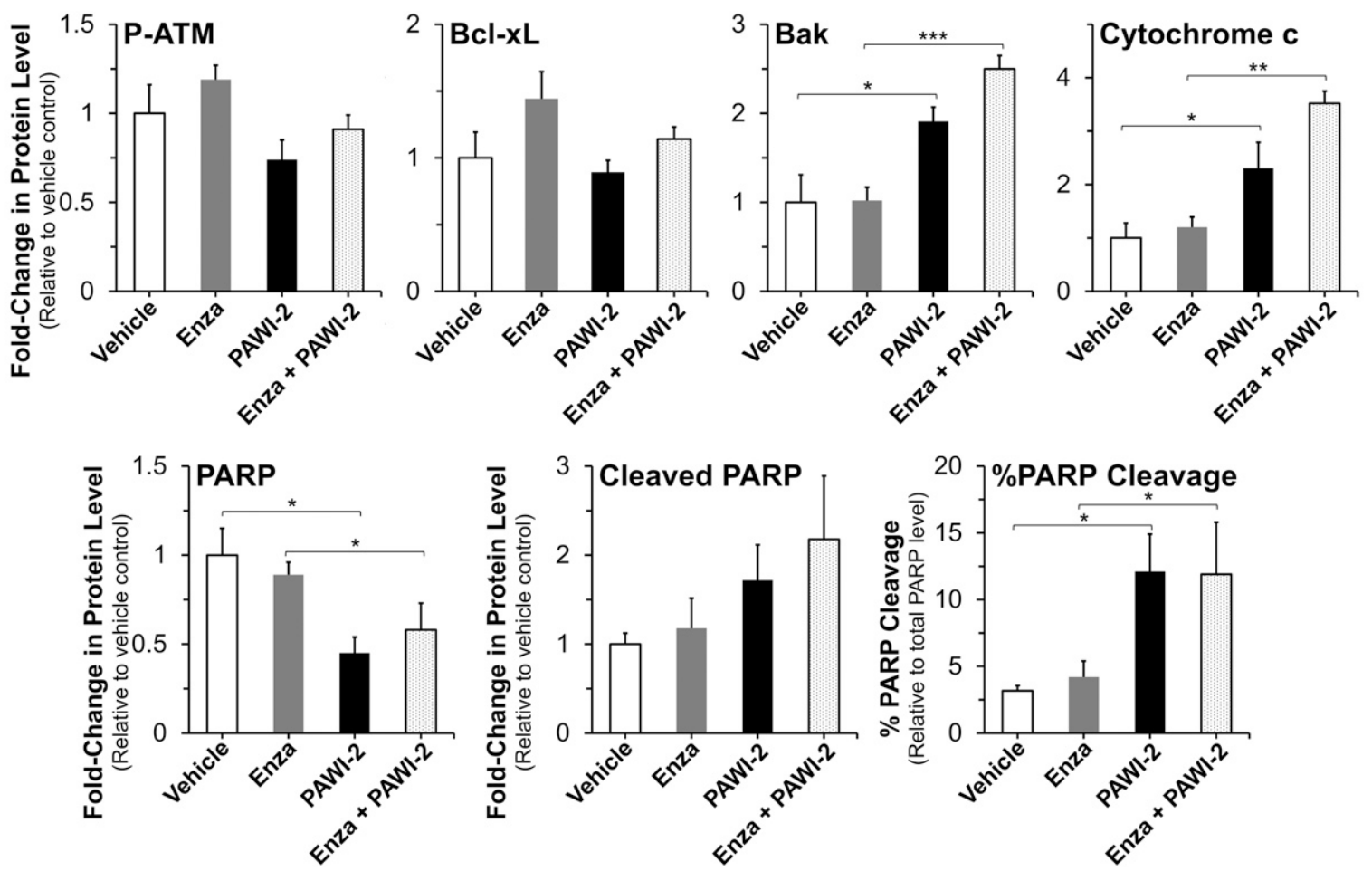

Fig. 5. (A and B) Immunoblot (A) and densitometry (B) analysis of phospho-Ser1981-ATM (P-ATM), Bcl-xL, Bak, cytochrome $c$, and PARP (PARP cleavage) proteins from tumor tissue extracts treated with vehicle (aqueous polyethylene glycol, $n=5$ ), enzalutamide $(n=8)$, PAWI-2 $(n=9)$, and combination of enzalutamide and PAWI-2 (Enza + PAWI-2; $n=5$ ). Tumors were excised from mice on day 21 of the study as shown in Fig. 4 . HSP90 was used as an internal control in (A). Data are means \pm S.E.M. in (B). $P$ values were estimated by the $t$ test $(* P<0.05 ; * * P<0.01 ; * * * P<0.001)$.

22RV1-CRPCa model, enzalutamide (20 mg/kg per day i.p., 22 days) afforded mice an estimated $15 \%$ inhibition of tumor growth (Kong et al., 2018). For PC-3 xenograft models, cabazitaxel ( $5 \mathrm{mg} / \mathrm{kg}$ per week i.p., 8 weeks) showed $18 \%$ inhibition (Zhang et al., 2013) and docetaxel (5 mg/kg b.i.w. i.p., 14 days) showed 35\% inhibition (Mimeault et al., 2015) of tumor growth, respectively. These are lower levels of tumor growth inhibition compared with treatment with PAWI-2 $(20 \mathrm{mg} / \mathrm{kg}$ per day, $49 \%$ inhibition) or enzalutamide + PAWI-2 (63\% inhibition; Fig. 4) with no observed toxicity (Supplemental Fig. 1; Supplemental Table 1). Thus, the data herein show that PAWI-2 is more efficacious than the most commonly used clinical treatment in an animal model of $\mathrm{PCa}$. In addition, compared with other CRPCa drugs (Wishart et al., 2018), the excellent pharmaceutical properties of PAWI-2 (absorption, distribution, metabolism, and excretion properties and lack of toxicity; Supplemental Table 2) also distinguish this druglike molecule from other PCa treatments. For example, acquired enzalutamide resistance is a hallmark of CRPCa (Li et al., 2018). Analysis of the pan-assay interference compounds (PAINS) alerts (Vidler et al., 2018) for PAWI-2 showed there were no apparent issues present for PAWI-2. Downregulation of prosurvival factors (e.g., Bcl-2, Bcl-xL, Mcl-1) and the imbalance of prosurvival and antisurvival factors caused by PAWI-2 through affecting mitochondrial membrane potential/function may be a controlling mechanism in synergizing/resensitizing the effect of enzalutamide to overcome enzalutamide resistance.

In summary, PAWI-2 is a nontoxic, highly efficacious compound for PCa that showed considerable synergism with enzalutamide to decrease PCa cell viability, migration, and invasion. PAWI-2 effectively inhibited tumor growth in 
a xenograft model of CRPCa cells (PC-3) as a single agent and also in combination with enzalutamide. Because of its novel mechanism of action, PAWI-2 has broad utility to treat more aggressive CRPCa and patient-derived bone niche CRPCa. PAWI-2 synergizes other PCa drugs and thus allows a lower dose, a decrease in toxicity, and a resensitization of the effect of other PCa drugs (e.g., enzalutamide).

\section{Acknowledgments}

We thank Dr. Christina Jamieson (Moores Cancer Center, University of California, San Diego) for the PCSD1 cells. We also thank Dr. John T. Isaacs (Sidney Kimmel Comprehensive Cancer Center, Johns Hopkins School of Medicine, Baltimore, MD) for the 11220hTERT cells.

\section{Authorship Contributions}

Participated in research design: Cheng, Okolotowicz, Cashman.

Conducted experiments: Cheng, Moore, Lee, Cashman.

Contributed new reagents or analytic tools: Cheng, Gomez-Galeno, Okolotowicz, Cashman.

Performed data analysis: Cheng, Moore, Lee.

Wrote or contributed to the writing of the manuscript: Cheng, Gomez-Galeno, Cashman.

\section{References}

Beer TM, Chowdhury S, Saad F, Shore ND, Higano CS, Iversen P, Fizazi K, Miller K, Heidenreich A, Kim CS, et al. (2018) Hepatic effects assessed by review of safety data in enzalutamide castration-resistant prostate cancer (CRPC) trials. J Clin Oncol 36:199.

Cashman JR, Mercola M, Schade D, and Tsuda M (2013) inventors, Human Biomolecular Research Institute and ChemRegen Inc., assignee. Compounds for inhibition of cancer cell proliferation. U.S. patent 13/748,770. 2016 Aug 2.

Cheng J, Dwyer M, Okolotowicz KJ, Mercola M, and Cashman JR (2018) A novel inhibitor targets both Wnt signaling and ATM/p53 in colorectal cancer. Cancer Res 78:5072-5083.

Cheng J, Okolotowicz KJ, Ryan D, Mose E, Lowy AM, and Cashman JR (2019) Inhibition of invasive pancreatic cancer: restoring cell apoptosis by activating mitochondrial p53. Am J Cancer Res 9:390-405.

Chou TC (2010) Drug combination studies and their synergy quantification using the Chou-Talalay method. Cancer Res 70:440-446.

de Bono JS, Logothetis CJ, Molina A, Fizazi K, North S, Chu L, Chi KN, Jones RJ, Goodman OB Jr, Saad F, et al. COU-AA-301 Investigators (2011) Abiraterone and increased survival in metastatic prostate cancer. N Engl J Med 364:1995-2005.

Dhingra R, Sharma T, Singh S, Sharma S, Tomar P, Malhotra M, and Bhardwaj TR (2013) Enzalutamide: a novel anti-androgen with prolonged survival rate in CRPC patients. Mini Rev Med Chem 13:1475-1486.

Ehrenberg B, Montana V, Wei MD, Wuskell JP, and Loew LM (1988) Membrane potential can be determined in individual cells from the nernstian distribution of cationic dyes. Biophys $J$ 53:785-794.

Gandhi J, Afridi A, Vatsia S, Joshi G, Joshi G, Kaplan SA, Smith NL, and Khan SA (2018) The molecular biology of prostate cancer: current understanding and clinical implications. Prostate Cancer Prostatic Dis 21:22-36.

Godebu E, Muldong M, Strasner A, Wu CN, Park SC, Woo JR, Ma W, Liss MA Hirata T, Raheem O, et al. (2014) PCSD1, a new patient-derived model of bone metastatic prostate cancer, is castrate-resistant in the bone-niche. $J$ Transl Med 12:275

Graham MK, Principessa L, Antony L, Meeker AK, and Isaacs JT (2017) Low p $16^{\text {INK4a }}$ expression in early passage human prostate basal epithelial cells enables immortalization by telomerase expression alone. Prostate 77:374-384

Jernberg E, Bergh A, and Wikström P (2017) Clinical relevance of androgen receptor alterations in prostate cancer. Endocr Connect 6:R146-R161.

Karantanos T, Corn PG, and Thompson TC (2013) Prostate cancer progression after androgen deprivation therapy: mechanisms of castrate resistance and novel therapeutic approaches. Oncogene 32:5501-5511.

Katzenwadel A and Wolf P (2015) Androgen deprivation of prostate cancer: leading to a therapeutic dead end. Cancer Lett 367:12-17.
Kong Y, Cheng L, Mao F, Zhang Z, Zhang Y, Farah E, Bosler J, Bai Y, Ahmad N, Kuang S, et al. (2018) Inhibition of cholesterol biosynthesis overcomes enzalutamide resistance in castration-resistant prostate cancer (CRPC). J Biol Chem 293 14328-14341.

Li Q, Deng Q, Chao HP, Liu X, Lu Y, Lin K, Liu B, Tang GW, Zhang D, Tracz A, et al (2018) Linking prostate cancer cell AR heterogeneity to distinct castration and enzalutamide responses. Nat Commun 9:3600.

Massie CE, Lynch A, Ramos-Montoya A, Boren J, Stark R, Fazli L, Warren A, Scott $\mathrm{H}$, Madhu B, Sharma N, et al. (2011) The androgen receptor fuels prostate cancer by regulating central metabolism and biosynthesis. EMBO J 30:2719-2733.

Mediavilla-Varela M, Pacheco FJ, Almaguel F, Perez J, Sahakian E, Daniels TR, Leoh LS, Padilla A, Wall NR, Lilly MB, et al. (2009) Docetaxel-induced prostate cancer cell death involves concomitant activation of caspase and lysosomal pathways and is attenuated by LEDGF/p75. Mol Cancer 8:68.

Mimeault M, Rachagani S, Muniyan S, Seshacharyulu P, Johansson SL, Datta K, Lin MF, and Batra SK (2015) Inhibition of hedgehog signaling improves the anticarcinogenic effects of docetaxel in prostate cancer. Oncotarget 6:3887-3903.

Mukherji D, Omlin A, Pezaro C, Shamseddine A, and de Bono J (2014) Metastatic castration-resistant prostate cancer (CRPC): preclinical and clinical evidence for the sequential use of novel therapeutics. Cancer Metastasis Rev 33:555-566.

Ni L, Llewellyn R, Kesler CT, Kelley JB, Spencer A, Snow CJ, Shank L, and Paschal $\mathrm{BM}$ (2013) Androgen induces a switch from cytoplasmic retention to nuclear import of the androgen receptor. Mol Cell Biol 33:4766-4778.

Okolotowicz KJ, Dwyer M, Ryan D, Cheng J, Cashman EA, Moore S, Mercola M, and Cashman JR (2018) Novel tertiary sulfonamides as potent anti-cancer agents. Bioorg Med Chem 26:4441-4451.

Qiao Y, Feng FY, Wang Y, Cao X, Han S, Wilder-Romans K, Navone NM, Logothetis C, Taichman RS, Keller ET, et al. (2016) Mechanistic support for combined MET and AR blockade in castration-resistant prostate cancer. Neoplasia 18:1-9.

Raheem O, Kulidjian AA, Wu C, Jeong YB, Yamaguchi T, Smith KM, Goff D, Leu H, Morris SR, Cacalano NA, et al. (2011) A novel patient-derived intra-femoral xenograft model of bone metastatic prostate cancer that recapitulates mixed osteolytic and osteoblastic lesions. J Transl Med 9:185.

Ritch CR and Cookson MS (2016) Advances in the management of castration resistant prostate cancer. BMJ 355:i4405.

Schalken J and Fitzpatrick JM (2016) Enzalutamide: targeting the androgen signalling pathway in metastatic castration-resistant prostate cancer. BJU Int $\mathbf{1 1 7}$ $215-225$.

Scher HI, Fizazi K, Saad F, Taplin ME, Sternberg CN, Miller K, de Wit R, Mulders P, Chi KN, Shore ND, et al.; AFFIRM Investigators (2012) Increased survival with enzalutamide in prostate cancer after chemotherapy. $N$ Engl J Med 367: 1187-1197.

Shoemaker RH (2006) The NCI60 human tumour cell line anticancer drug screen. Nat Rev Cancer 6:813-823.

Siegel RL, Miller KD, and Jemal A (2018) Cancer statistics, 2018. CA Cancer J Clin 68:7-30.

Sturge J, Caley MP, and Waxman J (2011) Bone metastasis in prostate cancer: emerging therapeutic strategies. Nat Rev Clin Oncol 8:357-368.

Tran C, Ouk S, Clegg NJ, Chen Y, Watson PA, Arora V, Wongvipat J, Smith-Jones PM, Yoo D, Kwon A, et al. (2009) Development of a second-generation antiandrogen for treatment of advanced prostate cancer. Science 324:787-790.

van Bokhoven A, Varella-Garcia M, Korch C, Johannes WU, Smith EE, Miller HL, Nordeen SK, Miller GJ, and Lucia MS (2003) Molecular characterization of human prostate carcinoma cell lines. Prostate 57:205-225.

Vidler LR, Watson IA, Margolis BJ, Cummins DJ, and Brunavs M (2018) Investigating the behavior of published PAINS alerts using a pharmaceutical company data set. ACS Med Chem Lett 9:792-796.

Wiedemann N and Pfanner N (2017) Mitochondrial machineries for protein import and assembly. Annu Rev Biochem 86:685-714.

Wishart DS, Feunang YD, Guo AC, Lo EJ, Marcu A, Grant JR, Sajed T, Johnson D, Li C, Sayeeda Z, et al (2018) DrugBank 5.0: a major update to the DrugBank database for 2018. Nucleic Acids Res 46:D1074-D1082.

Yang JC, Ok JH, Busby JE, Borowsky AD, Kung HJ, and Evans CP (2009) Aberrant activation of androgen receptor in a new neuropeptide-autocrine model of androgen-insensitive prostate cancer. Cancer Res 69:151-160.

Zarif JC and Miranti CK (2016) The importance of non-nuclear AR signaling in prostate cancer progression and therapeutic resistance. Cell Signal 28:348-356.

Zhang S, Wang Y, Chen Z, Kim S, Iqbal S, Chi A, Ritenour C, Wang YA, Kucuk O, and Wu D (2013) Genistein enhances the efficacy of cabazitaxel chemotherapy in metastatic castration-resistant prostate cancer cells. Prostate 73:1681-1689.

Address correspondence to: Dr. Jiongjia Cheng, Human BioMolecular Research Institute, 5310 Eastgate Mall, San Diego, CA 92121. E-mail: jcheng@ hbri.org 